\title{
A realidade da Assistência Social no âmbito dos CRAS e CREAS do Rio Grande do Norte identificada em ações fiscalizatórias do Ministério Público Estadual
}

\author{
The reality of Social Assistance in the context of CRAS and CREAS of Rio \\ Grande do Norte identified in supervisory actions of the State Public \\ Prosecutor
}

\begin{abstract}
Karina Tatiane da Costa Martins *
\section{Resumo:}

Este artigo apresenta uma análise dos Centros de Referência de Assistência Social (Cras) e Centros de Referência Especializados de Assistência Social (Creas) do Rio Grande do Norte (RN), a partir do exame da estrutura física, recursos humanos e serviços socioassistenciais, em face da Política de Assistência Social. Para tanto, objetiva de modo geral analisar as referidas unidades, por meio das informações obtidas, através da execução do Projeto Institucional Conviver Suas, desenvolvido pelo Ministério Público do Estado do Rio Grande do Norte, e especificamente compreender como vem se efetivando os Cras e Creas, perante a gestão estadual do Suas, de forma que apresenta a sistematização dessa experiência de trabalho. Utilizou-se como recursos metodológicos a análise bibliográfica e documental, consulta a sites oficiais e legislações pertinentes ao assunto. $O$ presente estudo constatou via dados do Conviver Suas que o RN possui um cenário caótico no âmbito dos Cras e Creas e que há indicativos significativos da inoperância do Governo Estadual frente o Suas.
\end{abstract}

Palavras-chave: Assistência social. Ministério Público Estadual. CRAS e CREAS. Rio Grande do Norte. Projeto Institucional Conviver Suas.

\begin{abstract}
:
This paper presents an analysis of the Social Assistance Reference Centers (Cras) and Specialized Reference Centers of Social Assistance (Creas) of Rio Grande do Norte (RN) from the examination of the physical structure, human resources and social assistance services before the policy Social Assistance. For this, objective generally analyze said units, through information obtained, through the execution of the Institutional Living SUAS Project, developed by the Public Ministry of Rio Grande do Norte state, and specifically understand how is it effecting the Cras and Creas, before the state management of the SUAS, so that presents the systematization of this work experience. It was used as methodological resources in the bibliographic analysis and document, consult the official websites and relevant legislation to the subject. This study found through Living SUAS data that $R N$ has a chaotic scenario in the context of Cras and Creas and that there significant indicative of inoperability the State Government before SUAS.
\end{abstract}

Keywords: Social Assistance. State Public Prosecutor. CRAS and CREAS. Rio Grande do Norte. Institutional Living SUAS Project.

\footnotetext{
* Universidade Federal do Rio Grande do Norte. Mestranda em Serviço Social pelo Programa de PósGraduação em Serviço Social da Universidade Federal do Rio Grande do Norte (PPGSS/UFRN). Email: karinataty@hotmail.com
} 


\section{Introdução}

A Política de Assistência Social é direito de todo cidadão que dela necessitar, conforme baliza a Constituição Federal de 1988 (art.203 e 204), sendo, portanto, política pública não contributiva que compõe o tripé da Seguridade Social (BRASIL, 1988). Nessa direção, infraconstitucionalmente a Lei no 8.742, de 7 de dezembro de 1993 - Lei Orgânica da Assistência Social (Loas), consolidada com a Lei no 12.435/2011, regulamenta a Política de Assistência Social, e dentre outros aspectos estabelece responsabilidades para os entes federal, estadual e municipal quanto à Assistência Social e fixa meios de monitoramento e fiscalização de suas ações.

A Constituição Federal de 1988 (BRASIL, 1988), além de instituir a Política de Assistência Social como política pública, também estabeleceu novo papel político e institucional ao Ministério Público, destinando a esta instituição capítulo próprio, desvinculado dos Poderes do Estado, tratando-o como órgão com "função essencial à justiça", fiscalizador da Lei e não parte do Poder Judiciário.

O Ministério Público ao exercer a função de fiscal da Lei, estabelece conexão com a Política de Assistência Social, por meio do art. 31 da Lei no 8.742/1993 - Loas, onde preconiza que cabe ao Ministério Público zelar pelo efetivo respeito aos direitos estabelecidos neste diploma legal. (BRASIL, 1993).

Ante este dispositivo, Ministério Público do Estado do Rio Grande do Norte (MPRN), ao exercer o papel constitucional de fiscalizador da Lei, especialmente das leis que regulamentam a Política de Assistência Social, resolveu na matéria da Infância, Juventude e Família, lançar no ano de 2010, por meio do Centro de Apoio Operacional às Promotorias de Justiça de Defesa da Infância, Juventude e Família (CAOP Infância, Juventude e Família - CAOPIJF), o Projeto Institucional Conviver SUAS, com o escopo de contribuir para a elevação do padrão de atendimento realizado na Assistência Social às famílias, crianças e adolescentes, nos municípios do Estado do Rio Grande do Norte (RN).

O referido Projeto abrangeu visitas institucionais entre os anos de 2010 a 2015, especialmente, aos Centros de Referência de Assistência Social (Cras) e Centros de Referência Especializados de Assistência Social (Creas), detendo-se a fiscalizar essencialmente três aspectos, a estrutura física, os recursos humanos e os serviços socioassistenciais, o que permitiu ao MPRN conhecer de perto a realidada da assistência 
social no Estado do RN, frente as normativas do Sistema Único de Assistência Social (Suas).

Com base nisso, apresenta-se neste artigo uma análise da realidade da Política de Assistência Social no RN, no âmbito dos Cras e Creas, consoante o que dispõe a Lei no 8.742/1993 - Loas e outras normativas Suas, descortinada, a partir das informações e dados obtidos, por meio da execução Projeto Institucional Conviver Suas.

Para tanto, este artigo apresenta a sistematização dessa experiência de trabalho e tem como objetivo geral analisar os Cras e Creas do RN, a partir do exame da estrutura física, dos recursos humanos e serviços socioassistenciais, em face da Política de Assistência Social, conforme o que dispõe a Lei no 8.742/1993 - Loas e outras normativas do Suas, a partir das informações obtidas, por meio da execução do Projeto Institucional Conviver Suas, e especificamente compreender como vem se efetivando os Cras e Creas, perante a gestão estadual do Suas.

O presente artigo, torna-se relevante em razão da Política de Assistência Social estar em constante transformação, requerendo dos órgãos responsáveis atenção quanto à fiscalização do cumprimento de suas normas, o que exige ação direta do Ministério Público, como fiscal da Lei. Além disso, o MP estabelece interface cotidiana com as ações socioassistenciais, principalmente na matéria da infância, juventude, família e idoso, fazendo-se necessário divulgar amplamente como esta instituição exerce a fiscalização desta Política e em que medida isso contribui para melhoria da Assistência Social.

Ademais, há poucos trabalhos no RN sobre o papel do Ministério Público perante as ações socioassistenciais, e além do mais o Estado do RN possui um histórico de inoperância frente à execução da Política de Assistência Social, o que desperta inquietações sobre a temática, buscando compreender as suas razões.

Outrossim, o estímulo para elaboração desse artigo partiu de vivências profissionais na área da criança e do adolescente e do envolvimento com o assunto em alguns órgãos, principalmente no MPRN.

Para compor esse artigo, utilizaram-se como recursos metodológicos a análise bibliográfica e documental dos dados do Projeto Conviver Suas, consulta a sites oficiais e legislações pertinente ao assunto e correlata. 
Este artigo classifica-se como artigo original (de divulgação), e está dividido em seis partes. Inicia-se pela introdução, seguida de um breve histórico da Política de Assistência Social no Brasil, na sequência faz-se uma análise da Política de Assistência Social no RN, posteriormente discute-se sobre a interface do Ministério Público com a Política de Assistência Social, acompanhado da apresentação do Projeto Conviver Suas; em seguida apresentam-se as constatações do referido Projeto, como ação fiscalizatória do Ministério Público do Estado do Rio Grande do Norte (MPRN), e por fim as considerações finais.

\section{A política de assistência social no Brasil: das raízes históricas à contemporaneidade}

Segundo Sposati et al. (1995), a assistência ao outro é um ato antigo na humanidade, principalmente àqueles historicamente taxados como pobres, desprovidos. Para a autora "a assistência não se limita nem à civilização judaico-cristã nem às sociedades capitalistas". Ela é uma prática adotada por milhares de anos entre os comuns e exercida ao longo do tempo por filantrópicos e religiosos. (SPOSATI et al., 1995, p. 40).

De acordo Sposati et al. (1995), no Brasil, a assistência social passou por inúmeras transformações até se configurar como política pública, conforme se apresenta na contemporaneidade. Segundo a autora nas terras brasileiras durante anos as condições de pobreza que aflingiam a população foram tratadas como disfunção social dos indivíduos. Assim, por décadas neste país as condições agudizadas de pauperização da população foram concebidas de forma benevolente de cunho religioso e de caridade, sem apoio do Estado.

Segundo Saraiva (2005), ao se reproduzir esse tratamento aos pobres, o atendimento às necessidades da população foi durante os primeiros quatrocentos anos do Brasil, função exercida pela Igreja Católica. Registra-se que desde a chegada dos colonizadores até $\mathrm{O}$ início do século $\mathrm{XX}$, houve total ausência do Estado no desenvolvimento de ações públicas e sociais.

De acordo com Sposati et al. (1995), até o ano de 1930 a pobreza não era apreendida como expressão da questão social ${ }^{1}$, dada a situação conjuntural do País.

\footnotetext{
1 Segundo lamamoto (2008), questão social é o conjunto das expressões das desigualdades da sociedade capitalista madura.
} 
Segundo a autora, nesse período a pobreza era enquadrada pelo Estado como "caso de polícia" e tratata no interior de seus aparelhos repressivos.

Com o ínicio da Era Vargas, que durou quinze anos ininterruptos (1930-1945), houve a regulamentação paulatina das relações do trabalho que culminou, segundo Behring e Boschetti (2006), com a introdução da política social no país.

Destaca-se como conquistas da era Vargas, a carteira de trabalho, as férias, as caixas de aposentadoria e pensão, dentre outras, no entanto essas conquistas, eram primordialmente, para aqueles que estavam formalmente inseridos no mundo do trabalho, de forma que, os desempregados e outros totalmente despossuídos não usufruiam desses dirietos, permanecendo a margem da sociedade, amparados pelas redes de solidariedade e caridade filantrópica ou religiosa.

O marco legal da responsabilização do Estado com as expressões da questão social, especialmente com as condições de pauperização da população, ocorreu somente na década de 1980, com a promulgação da Constituição Federal de 1988. No entanto frisa-se que no quadro sócio-histórico em que se concebeu a Assistência Social com status de política pública muita lutas foram travadas e todas marcadas por processos de avanços e retrocessos, devido à conjuntura política econômica que atravessaram esse período, fazendo refluir movimentos sociais e conquistas em curso (IAMAMOTO, 1994).

O advento dessa Carta Magna, permitiu consagrar expresso no art. 203, a assistência social como política pública de direito e proteção social. Sendo esta, concebida como um direito do cidadão e prestada a quem dela necessitar, independentemente de contribuição à seguridade social (BRASIL, 1988).

Com a preconização desse direito, oficialmente se instituiu as bases da política de assistência social no Brasil, oportunizando consequentemente a criação de documentos infraconstitucionais posteriores voltados a sua regulamentação, os quais por sua vez deram conteúdo e forma ao seu funcionamento.

Na cadência histórica desses documentos destaca-se como marcos normativos, a Lei Orgânica de Assistência Social - Loas (BRASIL, 1993), atualmente consolidada com a Lei 12.435/2011 (BRASIL, 2011), a Política Nacional de Assistência Social - PNAS (BRASIL, 2004), o Sistema Único de Assistência Social - Suas (BRASIL, 2005), regulamentado em 
2011, pela Lei que consolida a Loas², bem como Normas Operacionais Básicas (a Norma Operacional Básica do Suas - NOB/Suas - 2005/2012³ e a Norma Operacional Básica de Recursos Humanos do Suas - NOB-RH/Suas - 2006), e a Tipificação Nacional de Serviços Socioassistenciais (2009 e 2014), dentre outros documentos.

Com base nesses documentos, especialmente a Lei $n=8.742 / 1993$ - Loas (BRASIL, 1993), a assistência social passou a se configurar sob a forma de sistema descentralizado e participativo, denominado Sistema Único de Assistência Social (Suas), tendo como foco a matricialidade sociofamiliar e as ações passaram a ser organizar sob dois tipos de proteção: Proteção Social Básica (PSB) e Proteção Social Especial (PSE), sendo esta última subdividida em PSE de média e alta complexidade. A PSB voltada a ações preventivas e PSE a ações de enfrentamento das situações de violação de direitos.

Segundo a Loas, as proteções sociais básica e especial, deverão ser ofertadas precipuamente no Centro de Referência de Assistência Social (Cras) e no Centro de Referência Especializado de Assistência Social (Creas), respectivamente, e pelas entidades sem fins lucrativos de assistência social de que trata o art. 3일 desta Lei (art. 6--C, incluído pela Lei $n$ ㅇ 12.435, de 2011).

Os Cras, conforme a Loas configuram-se como unidades públicas municipais, de base territorial, localizados em áreas com maiores índices de vulnerabilidade e risco social, destinados à articulação dos serviços socioassistenciais no seu território de abrangência e à prestação de serviços, programas e projetos socioassistenciais de proteção social básica às famílias (art. 6ㅇ-C, § 1으, incluído pela Lei no 12.435, de 2011).

Os Creas por sua vez, a Loas define como unidades públicas de abrangência e gestão municipal, estadual ou regional, destinados à prestação de serviços aos indivíduos e famílias que se encontram em situação de risco pessoal ou social, por violação de direitos ou contingência, que demandam intervenções especializadas da proteção social especial (BRASIL, 2011, art. 6ㅇ-C, § 2ㅇ).

Segundo dados apontados pelo Instituto Brasileiro de Geografia e Estatística (IBGE, 2015), por meio da Pesquisa de Informações Básicas Municipais (Munic), ocorrida em

\footnotetext{
${ }^{2}$ Art. 60 da LOAS - " A gestão das ações na área de assistência social fica organizada sob a forma de sistema descentralizado e participativo, denominado Sistema Único de Assistência Social (Suas) [...] (Redação dada pela Lei no 12.435, de 2011). (BRASIL, 2011).

${ }^{3}$ A primeira em 2005, a qual atualmente encontra-se revogada pela Resolução $n$ ㅇ 33, de 12 de dezembro de 2012, aprovada pelo Conselho Nacional de Assistência Social, hoje em vigor.
} 
2009, discutida pelo conjunto Cfess-Cress, na publicação "Trabalhar na Assistência Social em defesa dos direitos da Seguridade Social" (CONSELHO FEDERAL DE SERVIÇO SOCIAL 2011), após a criação do Suas, o quadro de trabalhadores da Assistência Social teve um acréscimo de 30,7\% entre 2005 e 2009, visto que o número saltou de 139.549 trabalhadores em 2005 para 182.436 em 2009.

Entretanto, segundo Brisola e Silva (2014), contrapondo-se a esse aumento nos postos de trabalho as condições e relações de trabalho não acompanharam o mesmo ritmo, declinando inversamente, sendo marcadas até a contemporaneidade pela precarização na política, o que revela a contraditória relação entre capital trabalho e entre o papel da politica social no capitalismo.

Com efeito, na Assistência Social as relações e condições de trabalho são resultante da dinâmica dos processos sociais contemporâneos, baseadas na flexibilização, exploração, espoliação e terceirização, enquanto que sua efetivação como política social nos limites do capital ocorre com fortes tendências à focalização, a descentralização e a precarização, com parcos suspiros de ascensão da classe subalterna, servindo para manter o status quo predominante. (BRISOLA; SILVA, 2014).

De modo geral, no percorrer da trajetória histórica da Política de Assistência Social, observa-se ao longo do tempo que houve um salto paulatino de práticas caritativas e benevolentes de cunho religioso a constituição de uma política pública de direito, que amparada num rol de normas e lutas, vem se regulamentando dando forma e conteúdo as suas ações.

Esse fio condutor de lutas e regramentos da Política de Assistência Social como política pública de direito, torna-se um desafio cotidiano nos diversos espaços, visto que práticas assistencialistas não foram extirpadas. Com base nesse desafio presente constantemente nas entidades/orgãos de atendimento, o próximo tópico apresenta uma análise sobre a execução da Política de Assistência Social no Rio Grande do Norte, buscando compreender os limites e as possibilidades da sua efetivação.

\section{A política de assistência social no Rio Grande do Norte: realidade e legalidade}

O Estado do Rio Grande do Norte (RN) circunscreve-se no Nordeste do Brasil, compondo uma das 27 unidades federativas do país. De acordo com dados do Instituto 
Brasileiro de Geografia e Estatística (IBGE, 2015), o RN abrange uma área total de 52. $811,126 \mathrm{~km}^{2}$, possui 3.168 .027 habitantes, distribuídos em 167 municípios. Ocupa a 18o posição no Produto Interno Bruto (PIB) do país. Seu Índice de Desenvolvimento Econômico (IDH) em 2014 foi de 0,744.

Segundo dados do Ministério do Desenvolvimento Social e Agrário (MDSA), o RN possui cerca de 335.694 famílias cadastradas no Cadastro Único, com renda per capita mensal de $\mathrm{R} \$ \mathbf{0 , 0 0}$ até $\mathrm{R} \$ \mathrm{77}$, o que representa um dado expressivo de famílias em situação de pobreza e extrema pobreza no Estado necessitando da Política de Assistência Social, isto é, dos programas, projetos, serviços e benefícios ofertados.

Com base nos dados MDSA, o RN possui ativados 218 Centros de Referência de Assistência Social (Cras), 56 Centros de Referência Especializados de Assistência Social (Creas); 2 Centros de Referência Especializados de Assistência Social para População em Situação de Rua (Centro POP); 1 Centro Dia; 1 Residência Inclusiva; 20 unidades de acolhimento institucional para criança e adolescente, e vários núcleos do Serviço de Convivência e Fortalecimento de Vínculos (SCFV)(BRASIL, 2015).

A execução estadual da Política de Assistência Social é de responsabilidade da Secretaria de Estado do Trabalho, da Habitação e da Assistência Social (Sethas), que tem por missão institucional "Planejar e desenvolver projetos e programas nas áreas do Trabalho, Habitação e Assistência Social em todo o Rio Grande do Norte". (RIO GRANDE DO NORTE, 2015c).

A Sethas possui o quadro de recursos humanos predominantemente formado por cargos comissionados e cedidos, encontrando-se atualmente com déficit de pessoal e com muitos profissionais em fase de aposentadoria, gerando com isso a descontinuidade das ações e o descumprimento da NOB-RH/SUAS, onde se estabelece que o quadro de pessoal deve ser formado por meio de concurso público ${ }^{4}$. Além disso essa realidade coaduna com os apontamentos de Brisola e Silva (2014) anteriormente citados sobre a precarização das relações de trabalho.

Quanto a estrutura física a Sethas comporta um prédio subdividido em dois espaços, na parte de baixo funciona a Fundação Estadual da Criança e do Adolescente (Fundac), que é vinculada a Sethas e possui os mesmos problemas de recursos humanos

\footnotetext{
${ }^{4}$ Informações colhidas a partir de investigações da 21a Promotoria de Justiça de Natal.
} 
enfrentados por esta Secretaria, e na parte superior a própria Sethas, de forma que ambas realizam ações de cunho socioassistencial de ordem governamental ${ }^{5}$.

Nessa díade entre a Sethas e a Fundac responsabilidades são divididas. A Sethas fica responsável por administrar em âmbito estadual o Programa Bolsa Família, os Cras, os Creas, os SCFV, o Programa Cisternas, os Restaurantes Populares, o Programa de Artesanato Potiguar (Proart), o Café do Trabalhador, o Projeto Catadores, o Benefício de Prestação Continuada (BPC), e a Economia Solidária.

Já a Fundac, atualmente, fica responsável por administrar a Coordenadoria de Programas de Proteção Especial (CPPE), que abrange as unidades de atendimento socioeducativo em regime de semiliberdade e em meio fechado para adolescentes autores de ato infracional; a Coordenadoria de Programas Específicos (CPE), que abrange unidades de atendimento às crianças e adolescentes em situação de rua e cursos profissionalizantes; e a Coordenadoria de Ações Integradas (CAI), que abrange programas voltados à formação e encaminhamento de adolescentes ao trabalho, e setores da saúde, nutrição, cultura, esporte e lazer.

A Fundac por se responsabilizar pela CPPE foi responsável até o ano de 2014, também pelas unidades estaduais de acolhimento para crianças e adolescentes, porém o sistema socioeducativo e as unidades de acolhimento entraram em colapso (foram interditadas) sob sua administração, dado os vestígios de precarização na estrutura física, nos recursos humanos e na prestação dos serviços de ambos, sinalizados nos anos anteriores pelas autoridades.

Atualmente, devido a investigações e denúncias dos órgãos de fiscalização a Fundac está sob intervenção judicial, ficando responsável apenas pelo sistema socioeducativo, enquanto que os serviços de acolhimento foram transferidos para a Sethas, que enfim assumiu sua responsabilidade como gestora estadual da assistência social ${ }^{6}$.

No que tange ao financiamento da Política de Assistência Social, em 1995 foi criado o Fundo Estadual de Assistência Social (Feas), por meio da Lei Estadual no 6.844, de 27 de dezembro de 1995. Essa Lei prevê que sejam efetuados repasses diretos e automáticos de

5 As informações sobre a estrutura e funcionamento da Sethas e da Fundac foram extraídas do site da Sethas e da Fundac (RIO GRANDE DO NORTE, 2015a, 2015c).

${ }^{6}$ Devido a esse desvio de rota, o Ministério Público do Estado do Rio Grande do Norte, desde 2011 quando interditou as unidades, por meio de tratativas vem exigindo o cumprimento das responsabilidades no âmbito do Suas por parte do Estado, especificamente da Sethas. 
recursos financeiros para os fundos municipais de assistência social e ainda estabelece repasses para os serviços de média e alta complexidade de forma regionalizada.

Destarte, diante desse dispositivo legal, o Estado no RN deveria cofinanciar por meio da Sethas as ações socioassistenciais desde 1995, principalmente de forma regionalizada e cumprir com as responsabilidades estaduais no âmbito do Suas. No entanto, esse cofinanciamento nunca aconteceu, segundo, ações fiscalizatórias empreendidas pelo Ministério Público do Estado do Rio Grande do Norte (MPRN), ao cumprir o art. 31 da Loas.

A falta desse cofinanciamento agrava ainda mais a situação da assistência social do RN, visto que a maioria dos municípios do Estado são de Pequeno Porte 1 e $2^{7}$, segundo a classificação dos municípios adotada pela PNAS, o que significa dizer que dos 167 municípios do RN, 160 precisam da oferta de serviços de média e alta complexidade de forma cofinanciada e regionalizada, que segundo a NOB/SUAS são os efetivos serviços de responsabilidade estadual.

Em outras palavras, a Sethas em cumprimento a Loas (II, art.13) e a NOB/SUAS (art.15), obrigatoriamente deveria ofertar e cofinanciar em 160 municípios do RN serviços de média e alta complexidade de forma regionalizada, incluindo os serviços de acolhimento, e não o faz, representando com isso um dos maiores entraves das ações socioassistenciais em âmbito estadual.

Em 2014, com a assumpção das responsabilidades dos serviços de acolhimento para crianças e adolescentes pela Sethas, o MPRN exigiu que a mesma cofinanciasse os serviços de média e alta complexidade, visto que não havia até então, nenhum cofinanciado. Assim, desde o final de 2014, a SETHAS vem empreendendo esforços para assumir sua função.

Frente a essa exigência, a Sethas em articulação com o MPRN e demais órgãos socioassistenciais, inaugurou em 2014, com dificuldade a primeira unidade regionalizada de acolhimento para crianças e adolescentes no município de Extremoz/RN, reabrindo a oferta de acolhimento que havia se esgotado com a interdição das unidades antes

\footnotetext{
${ }^{7}$ De acordo com a PNAS, os municípios são classificados como de Pequeno Porte 1, Pequeno Porte 2, Médio Porte, Grande Porte e Metrópoles. Os de pequeno porte 1 são aqueles com o número de até 20.000 habitantes, e os de pequeno porte 2 são aqueles, cujo número de habitantes varia entre 20,001 até 50.000. (BRASIL, 2004, p. 45-46).
} 
existentes. Além disso, assinou termos de aceite do MDSA para cofinanciar de forma regionalizada seis Creas e 192 vagas para os serviços de acolhimento para crianças e adolescentes.

Em conjunto com a Sethas o MPRN objetivando o avanço dessas ações, e diante da inoperância da gestão estadual do Suas, elaborou um cronograma que exige a abertura de outras seis unidades de acolhimento, sendo uma em cada região do Estado, até o ano de 2017. A meta estipulada é inaugurar uma unidade a cada seis meses, caso não haja atrasos.

Além disso, o poder judiciário do RN, por meio da Resolução № 12/2014, aprovou foros regionais da infância e juventude nas mesmas cidades pólos onde a Sethas e o MPRN elegeram para implantar as unidades regionalizadas, ou seja, para cada unidade haverá um juiz responsável dando celeridade aos processos.

Com a implantação da unidade de acolhimento regional em Extremoz/RN e as futuras seis unidades planejadas, o Estado comportará sete unidades regionais melhorando o presente quadro deficitário. Somado a isso, no intuito de melhorar esse quadro o MPRN em paralelo ao cronograma destas futuras seis unidades regionais de abrigo institucional, lançou por meio do Centro de Apoio Operacional às Promotorias de Defesa da Infância, Juventude e Família (CAOP Infância, Juventude e Família - CAOPIJF), em agosto de 2014, o Projeto Abrace Vidas voltado ao fomento do acolhimento familiar no Estado. Com esse Projeto a proposta do MPRN é quadruplicar o número de municípios que oferecem os serviços de acolhimento às crianças e adolescentes até o final de 2015.

Outrossim, o MPRN vem descortinando através de suas fiscalizações outras problemáticas na área da Assistência Social estadual, como será visto adiante no âmbito dos Cras e Creas, por meio do Projeto Institucional Conviver Suas.

Com base nessa breve exposição sobre o desenho da assistência social no Rio Grande do Norte, apresenta-se no próximo tópico alguns dados sobre os Cras e Creas do RN apreendidos pelo Ministério Público do Estado do Rio Grande do Norte, na execução do Projeto Institucional Conviver Suas.

\section{A interface do Ministério Público do Estado do Rio Grande do Norte com a política de assistência social: a experiência do projeto Conviver SUAS}


O Ministério Público, enquanto instituição recebeu novo papel político e institucional, a partir da Constituição Federal de 1988. A esta instituição foi destinado capítulo próprio, desvinculado dos Poderes do Estado, tratando-o como órgão com "função essencial à justiça” e não parte do Poder Judiciário.

Segundo Souza (2007), essa Carta Política delegou ao Ministério Público papel preponderante na implementação e na manutenção do Estado Democrático de Direito, o que requer necessariamente o dever de participar ativamente do processo de construção da cidadania, zelando pela efetividade dos direitos fundamentais.

No que se refere à Política de Assistência Social, o art. 31 da Lei no 8.742/1993 Loas, preconiza que cabe ao Ministério Público zelar pelo efetivo respeito aos direitos estabelecidos neste diploma legal (BRASIL, 1993). Ante este dispositivo, foram formuladas pelo Conselho Nacional do Ministério Público (CNMP) resoluções que regulamentaram por meio de inspeção e ações de fiscalização o cumprimento dessa determinação.

Nessa perspectiva, o Ministério Público do Estado do Rio Grande do Norte, ao receber cotidianamente demandas da área da assistência social, sejam elas voltadas às denúncias sobre a falta de condições de funcionamento dos serviços ou desvio de verbas, bem como de usuários que passaram pelos serviços, mas não tiveram êxito nos atendimentos, somado à cristalina inoperância do Governo e da gestão Estadual frente ao Suas, resolveu lançar o projeto institucional Conviver Suas ${ }^{8}$ para se aproximar dessa realidade, a fim de compreendê-la melhor e exigir o que determina a Loas.

Nesse sentido, o MPRN, na matéria da infância, juventude e família, por meio do Centro de Apoio Operacional às Promotorias de Justiça de Defesa da Infância, Juventude e Família (Caop Infância, Juventude e Família - Caopijf), lançou no ano de 2010, o Projeto Institucional Conviver $\mathrm{SUAS}^{9}$, com o escopo de contribuir para a elevação do padrão de

\footnotetext{
${ }^{8}$ O Projeto Conviver Suas foi lançado também em comemoração aos 20 anos de promulgação do Estatuto da Criança e do Adolescente (ECA), festejado no ano de 2010.

${ }^{9}$ Informa-se que a autora deste artigo, vivenciou experiência de trabalho no MPRN, lotada no CAOPIJF, entre os anos de 2011 a 2015, período em que ocupou o cargo de Assistente Ministerial - Área Serviço Social, de provimento em comissão, sendo responsável dentre outras atribuições por assuntos relacionados ao acolhimento de criança e adolescente e à assistência social. Em virtude disso, participou de ações fiscalizatórias nessa área, da organização e implementação dos acolhimentos regionais, de reuniões com o poder judiciário, Sethas e Fundac e da elaboração e implementação do Projeto Abrace Vidas e do Conviver SUAS, bem como de outras articulações nesse âmbito, sendo este artigo fruto dessa experiência de trabalho.
} 
atendimento realizado na Assistência Social às famílias, crianças e adolescentes, nos municípios do Estado RN.

Para executar este escopo, o Projeto abrangeu inicialmente, visitas técnicas às unidades socioassistenciais e aos órgãos gestores da assistência social, de forma que concentrou as visitas aos Centros de Referência de Assistência Social (CRAS), aos Centros de Referência Especializados de Assistência Social (CREAS), aos Coletivos de Projovem Adolescente, aos Núcleos do Programa de Erradicação do Trabalho Infantil (PETI) ${ }^{10}$ e às Unidades de Acolhimento Institucional. Posteriormente, limitou-se à realização de visitas aos Cras e Creas, em decorrência de alterações transitórias na Política Nacional de Assistência Social (PNAS).

Neste contexto, as visitas técnicas realizadas no âmbito desse Projeto tiveram o objetivo de identificar possíveis irregularidades nas unidades socioassistenciais, Cras e Creas, no que tange à estrutura física, recursos humanos e serviços socioassistenciais, e às dificuldades vivenciadas pelos municípios do Estado do RN, em observância às normativas do Sistema Único de Assistência Social.

O Projeto Conviver Suas foi desenvolvido durante os anos de 2010 a 2015, pela equipe do Caopij, especificamente sob a responsablidade direta de duas assistentes sociais, as quais realizaram toda operacionalização do Projeto.

O Conviver Suas foi aderido por 63 Comarcas, totalizando 154 municípios, o quê resulta numa adesão de $97 \%$ das Comarcas e 93\% dos municípios, já que ao todo, são 65 comarcas e 167 municípios no Estado ${ }^{11}$.

As visitas de inspeção do Projeto, nos Cras e Creas dos 154 municípios, foram realizadas em duas etapas, a primeira para fiscalizar a estrutura física e os recursos humanos, e a segunda para fiscalizar os serviços socioassistenciais. Dividiu-se dessa forma, porque a equipe constatou nas primeiras visitas realizadas, que não fazia sentido fiscalizar tudo de uma vez, posto que para um bom funcionamento dos serviços, a

\footnotetext{
10 Destaca-se que no ano de 2010, início da execução do Projeto Conviver Suas, ainda vigorava na Assistência Social os núcleos de Projovem Adolescente e PETIs, atuais Serviços de Convivência e Fortalecimento de Vínculos.

${ }^{11}$ Destaca-se que as visitas de inspeção no Município de Natal, capital do Estado do RN, não foram feitas pela equipe do Caopijf, vez que há uma Promotoria de Justiça (PmJ), a 21 a que possui dentre suas atribuições a fiscalização do Suas. Dessa forma, o inquérito civil de Natal foi repassado a 21a PmJ.
} 
príncipio deveria haver no mínimo estrutura física e recursos humanos compatíveis, conforme estabelece a Loas (Art. 6o - D e E).

A primeira etapa concentrou-se nos anos de 2011 a 2013, e a segunda a partir da metado do ano de 2013 a 2015. O ano de 2010 foi voltado apenas para organização administrativa do projeto, vez que a equipe responsável por sua execução só foi selecionada pelo Parquet no final de 2010 e início de $2011^{12}$.

Para operacionalizar o Conviver Suas, a equipe do Caopij utilizou como recursos metodológicos: a aplicação de formulários adequados a unidade visitada; entrevistas semi-estruturadas; observações técnicas; coleta de documentos institucionais; registro fotográfico; consultas a sites relacionados à Assistência Social e, por fim, análise documental as informações constantes nos Inquéritos Civis das Promotorias de Justiça (comarcas) que aderiram ao projeto.

A coleta de informações envolveu operadores diretamente e indiretamente do Suas, entre eles foram entrevistados assistentes sociais, psicólogos, pedagogos, advogados, educadores sociais, coordenadores das unidades e dos núcleos de atendimento, ambos com formações profissionais distintas, secretários (as), e em algumas ocasiões conselheiros tutelares, procuradores dos municípios e prefeitos, bem como promotores de justiça da comarca responsável.

Como produto dessas visitas, as assistentes sociais elaboraram relatórios e pareceres técnicos, listando as irregularidades/dificuldades encontradas, os quais posteriormente foram encaminhados à Promotoria de Justiça responsável, para que fosse celebrado o Termo de Ajustamento de Conduta (TAC) ou ajuizada a Ação Civil Pública (ACP) correspondente. Além disso, o Caopij disponibilizou material de apoio na intranet contendo modelos de TAC e ACP, entre outros, bem como elaborou minutas dessas peças personalizadas.

Registra-se de modo geral, que o MPRN, ao executar o Projeto Conviver Suas, em momento algum substituiu o papel da gestão estadual e municipal do Suas, no que tange as responsabilidades desses entes estabelecidas na Lei no 8.742/1993 - Loas e na Nob/Suas, como também não interferiu nas ações em âmbito nacional, de forma que

\footnotetext{
${ }^{12}$ A equipe inicial que executou o Conviver Suas foi formada por assistentes socais, em cargo de provimento em comissão, posteriormente a realização do Concurso Público da instituição, assistentes sociais efetivas assumiram o projeto.
} 
todas elas continuaram acontecendo paralelamente ao desenvolvimento do Projeto e conforme determinam as normas do Suas.

Nesse sentido, o Projeto Conviver Suas representou uma experiência pioneira no Nordeste, face uma ação do Ministério Público Estadual, e permitiu a instituição conhecer de perto a realidade e as lacunas da assistência social no Estado, tornando mais efetiva a exigência do cumprimento da Lei, especificamente, a Lei no 8.742/1993 - Loas. A seguir, apresenta-se algumas das constatações reveladas com o desenvolvimento do Projeto Conviver Suas.

\section{Projeto Conviver Suas: constatações obtidas}

O Projeto Conviver Suas desenvolvido pelo MPRN, por meio do Caop da Infância, Juventude e Família, durante os anos de 2010 a 2015, permitiu conhecer o atual quadro da assistência social no âmbito dos Cras e Creas do RN, de forma que se tornou possível identificar as principais problemáticas dessas unidades, no que tange a estrutura física, os recursos humanos e os serviços socioassistenciais.

Segue abaixo, algumas das constatações obtidas pela equipe do Caopij durante a execução do Projeto Conviver Suas ${ }^{13}$.

\section{Constatações quanto a estrutura física}

Relativo a esse aspecto, o Projeto Conviver Suas detectou como principais problemáticas as seguintes:

a) Estruturas precárias (alugadas ou cedidas), as quais dificultam a realização de reforma à adaptação dos espaços mínimos e não garantem a continuidade dos serviços socioassistenciais, principalmente quando ocorre mudança de gestão;

b) Falta dos espaços mínimos ${ }^{14}$, identificando-se que faltava principalmente salas para o atendimento (individual ou familiar), para o desenvolvimento das atividades

\footnotetext{
${ }^{13}$ Os dados ora expostos foram adensados no Relatório final do Projeto Conviver Suas, elaborado pela equipe do Caopij, em 2015. (RIO GRANDE DO NORTE, 2015a).

14 Segundo o guia de Orientações Técnicas do Cras (BRASIL, 2009a, p. 50-54) os espaços mínimos são recepção; sala de atendimento; sala de uso coletivo; sala administrativa; copa; e banheiros e segundo o guia de Orientações Técnicas do Creas (BRASIL, 2011a, p. 82-89) os espaços mínimos são recepção; sala de atendimento individual e outra familiar; sala administrativa; sala para atividades em grupos; copa, banheiros; espaços externos e almoxarifado ou similar. Quanto ao compartilhamento das unidades,
} 
administrativas e de coordenação e para realização de atividades em grupo/coletivas, detectando-se que na maioria das unidades esses ambientes eram inexistentes ou compartilhados entre si ou com outras estruturas administrativas externas as unidades;

c) Falta de organização dos espaços mínimos, visto que observou-se que a maioria das unidades não mantinham tais espaços organizados, conforme determinam os guias de orientações técnicas, isto é, não havia o mobiliário necessário, tampouco dimensão arquitetônica adequada;

d) Falta de acessibilidade, principalmente na entrada principal e nos banheiros;

e) Falta/inadequada placa de identificação das unidades e dos espaços mínimos;

f) Unidades pintadas com as cores do partido político da administração vigente e a existência de quadros com imagem do gestor (a) do executivo municipal.

Diante desses destaques, revela-se um quadro precário das estruturas físicas dos Cras e Creas do RN, formado em sua maioria por estruturas alugadas e cedidas, provisoriamente adaptadas para o funcionamento das unidades.

\section{Constatações quanto aos recursos humanos}

No tocante aos recursos humanos as principais inadequações constatadas com o Projeto Conviver Suas foram:

a) Precarização dos vínculos de trabalho encontrando-se contratos por tempo determinado, cargos em comissão e cessões, detectando-se alguns municípios com todo o quadro de pessoal da assistência social formado por profissionais com vínculo precarizado;

b) Falta de profissionais qualificados para desenvolver as funções essenciais à gestão do Suas, isto é, faltava profissionais no órgão gestor local do Suas para desenvolver as atividades própria da gestão ${ }^{15}$;

c) Falta de adequação dos cargos à NOB-RH/SUAS e a Resolução CNAS no 17/2011, detectando em detrimento destes, vários cargos desvinculados da assistência social;

\footnotetext{
observou-se que ocorria principalmente com os órgãos gestores locais da assistência social; Programa do Leite; Peti; e Projovem Adolescente.

15 De acordo NOB-RH/SUAS, as funções essenciais à gestão do Suas são coordenação da Proteção Social Básica (PSB) e da Proteção Social Especial (PSE); gestão municipal de assistência social; planejamento e orçamento; monitoramento e controle da execução dos serviços, programas, projetos e benefícios socioassistenciais; monitoramento e controle da Rede Socioassistencial; gestão do trabalho; e apoio às instâncias de deliberação.
} 
d) Falta de equipe mínima nas unidades Cras e Creas, principalmente de técnicos de nível médio, detectando-se que a função destes era absorvida na maioria das vezes pelos profissionais de nível superior;

e) Falta de capacitação para os trabalhadores do Suas, observando-se que a maioria dos municípios não investiam nesse quesito;

f) Sobrecarga de trabalho dos profissionais dos Cras e Creas, detectando-se na maioria das unidades que os profissionais eram compelidos a realizarem atividades que não pertenciam à esfera da assistência social e sim a outros órgãos interinstitucionais, causando prejuízo à execução dos serviços socioassistenciais; e

g) Falta/inadequado organograma do órgão gestor local do Suas à NOB-RH/SUAS.

Esses foram os problemas mais recorrentes nos municípios visitados, ficando claro que geralmente há um deficit de profissionais na área da assistência social, inclusive na execução dos serviços, além disso constatou-se que os municípios não investem em capacitação, apesar de serem responsáveis de forma compartilhada por essa função e ainda os profissionais sofrem com sobrecarga de trabalho da própria política e com demanda de outros órgãos interinstitucionais que não pertence à Assistência Social.

\section{Constatações quanto aos recursos materiais de consumo e permanentes}

Relativo aos recursos materiais de consumo e permanentes detectou-se com o Projeto Conviver Suas de modo geral, precárias condições de trabalho, conforme segue abaixo:

a) Falta de mobiliário adequado, principalmente armários e mesa alongada para o atendimento em conjunto pelos profissionais de nível superior;

b) Entre os recursos materiais permanentes e de consumo faltava, principalmente, computadores; máquina fotográfica; data show; aparelho de televisão, de som e de DVD; materiais socioeducativos (livros, revistas, jogos, brinquedos, CDs e DVDs); materiais esportivos; telefone e conexão à internet; e

c) Falta de automóvel(is) para a realização de visitas domiciliares, principalmente nas áreas dispersas do território (área rural), bem como para o atendimento das demandas dos serviços socioassistenciais.

Esse item foi incorporado a análise da estrutura física, vez que toda unidade Cras e Creas deve ser equipada com recursos materiais de consumo e de uso permanente. Dessa 
forma, a partir dos destaques acima realizados, constatou-se que falta na maioria das unidades equipamentos básicos para o funcionamento e logística dos serviços, causando assim, prejuízo a qualidade das ações.

\section{Constatações quanto aos serviços socioassistenciais}

No que tange aos serviços socioassistenciais as principais inadequações, detectadas com o Projeto Conviver Suas foram:

a) A falta de execução de alguns serviços, no Cras por exemplo, não se registrou nenhuma unidade executando o Serviço de Proteção Social Básica no domicílio para pessoas com deficiência e idosas, conforme estabelece a Tipificação Nacional de Serviços Sociassistenciais (Resolução CNAS no 109/2009, e no 13/2014). (BRASIL, 2009, 2014). Quanto ao Creas se observou que o Serviço Especializado em Abordagem Social era o menos executado nas unidades;

b) Observou-se de forma corriqueira a falta de capacitação e conhecimento das normas básicas da assistência social entre os profissionais, o que resultou na constatação da falta de organização e sistematização dos serviços. No Cras, notou-se consequentemente a falta de organização e entendimento do Serviço de Proteção e Atendimento Integral à Família (PAIF) e no Creas do Serviço de Proteção e Atendimento Especializado a Famílias e Indivíduos (PAEFI) e do Serviço de Proteção Social a Adolescentes em Cumprimento de Medidas Socioeducativa de Liberdade Assistida (LA), e de Prestação de Serviços à Comunidade (PSC);

c) Verificou-se que as precárias condições da estrutura física e dos recursos humanos prejudicam demasiadamente a execução dos serviços, pois a falta de espaço físico dificulta o desenvolvimento dos serviços, assim como a falta de recursos humanos (equipe mínima);

d) Sobrecarga de trabalho, observando-se que em quase $100 \%$ das unidades Cras e Creas visitadas, os profissionais eram compelidos a realizarem atividades que não pertenciam à esfera da assistência social e sim ao Poder Judiciário, ao Conselho Tutelar, às delegacias especializadas, entre outros órgãos, tais como demandas voltadas à verificação de denúncias do Disque 100, do Conselho Tutelar; adoção; guarda; interdição; psicoterapia; indisciplina escolar; laudo; perícia; saúde mental, entre outras. Observando- 
se que ao desenvolver essas atividades os serviços socioassistenciais das unidades eram prejudicados ou não eram desenvolvidos, precarizando, principalmente a execução dos serviços primordiais, no Cras o Serviço de Proteção e Atendimento Integral à Família (Paif) e no Creas o Serviço de Proteção e Atendimento Especializado às Famílias e Indivíduos (Paefi);

Registra-se que a análise dos serviços socioassistenciais durante a execução do Projeto Conviver Suas foi realizada com cautela, vez que se deu justamente no período do processo de reordenamento destes pelo MDSA. No entanto, diante dos destaques acima realizados, observa-se que a falta de capacitação e a sobrecarga de trabalho dos profissionais por outros órgãos interinstitucionais são os fatores que mais prejudicam a realização dos serviços socioassistenciais.

Além dessas constatações nos Cras e Creas, foi possível por meio do Projeto Conviver Suas, apurar que todos os 154 municípios visitados, reclamaram da falta de operatividade da gestão estadual do Suas. Segundo eles, a Sethas não prestava por nenhum meio de comunicação o devido suporte técnico aos municípios, não cofinanciava e nem fiscalizava as ações, e não capacitava os profissionais, deixando-os sem cobertura de qualquer amparo técnico.

De modo geral, essas foram as principais irregularidades/dificuldades detectadas nos Cras e Creas do RN fiscalizados durante a execução do Projeto Conviver Suas, o que revela ao analisar tais dados, um quadro caótico da assistência social, e principalmente lacunas na gestão do Estado frente às responsabilidades do Suas, visto que não cofinancia as ações, não presta suporte técnico as equipes, não executa suficientemente ações regionalizadas, tampouco elabora capacitações, apresentando indícios significativos de inoperância.

\section{Considerações Finais}

O trabalho ora exposto, propôs apresentar uma análise dos Centros de Referência de Assistência Social (Cras) e Centros de Referência Especializados de Assistência Social (Creas) do Rio Grande do Norte, a partir do exame da estrutura física, recursos humanos e serviços socioassistenciais, por meio de dados coletados através do Projeto Institucional 
Conviver Suas, desenvolvido pelo Caop Infância, Juventude e Família, do Ministério Público do Estado do Rio Grande do Norte.

Ao realizar a análise pretendida, inferiu-se após a introdução, no primeiro tópico que nem sempre existiu uma política de assistência social nos moldes atuais, visto que a assistência social no passado se constituia de práticas advindas de grupos filantrópicos e religiosos sem amparo do Estado, e não uma política pública de direito como é hoje em dia.

No segundo tópico, observou-se ao descrever como vem se configurando a política de assistência social no Rio Grande do Norte, que ocorre uma série de falhas na condução da política pela gestão estadual do Suas, principalmente no que tange ao descumprimento da Lei no 8.742/1993 - Loas e das próprias leis estaduais, refletidas com destaque na falta de confinanciamento das ações socioassistenciais, de suporte técnico aos municípios e serviços regionalizados.

No terceiro tópico, versou-se sobre dois assuntos, o primeiro relacionado à forma como acontece à interface do Ministério Público com a Política de Assistência Social, e o segundo destinado a desvelar o Projeto Conviver Suas.

No que tange ao primeiro assunto, verificou-se que o art. 31 da Lei no 8.742/1993 Loas, legitima a conexão da instituição com a política, à medida que fixa que cabe ao Ministério Público zelar pelo cumprimento da Loas, reafirmando assim o papel constitucional da instituição como fiscal da Lei, que também é instrumentalizado pelo CNMP por meio de resoluções que estabelecem a forma como a fiscalização deve acontecer.

Quanto ao segundo assunto, observou-se que o referido Projeto se trata de uma ação estratégica do MPRN, desenvolvida por meio de fiscalizações nos Cras e Creas, para que o Parquet se aproxime da realidade da assistência social e possa cobrar o cumprimento das normativas do Suas de forma mais acertiva. Além disso, o Projeto representou uma ação desafiadora e pioneira no RN/Nordeste.

Em seguida, no último tópico, apresentou-se os dados relevantes extraídos dos Cras e Creas do RN, no que tange à estrutura física, os recursos humanos e serviços socioassistenciais, obtidos por meio do Projeto Conviver Suas, em face da política de assistência social. O que revelou um rol de irregularidades e dificuldades recorrentes em 
todo o Estado, configurando um quadro atualmente precário e inoperante por parte da gestão estadual.

Diante do exposto, tornou-se possível depreender-se que a realidade da Política de Assistência Social no Rio Grande do Norte, no âmbito dos Cras e Creas, consoante o que dispõe a Lei no 8.742/1993 - Lei Orgânica da Assistência Social (Loas) e outras normativas Suas, a partir dos dados revelados pelo Projeto Conviver Suas está aquém das normativas vigentes, o que requer da gestão estadual imediato cumprimento das competências e responsabilidades estabelecidas nas normas do Suas, descarrilhando também na continuidade das fiscalizações promovidas pelas instâncias deliberativas do Suas e do Ministério Público do Estado do Rio Grande do Norte, sendo este último não mais por meio de projeto pontual, mas sim através de atividades perene.

\section{Referências}

BEHRING, E. R.; BOSCHETTI, I. Política social: fundamentos e história. São Paulo: Cortez, 2006.

BRASIL. Constituição (1988). Constituição da República Federativa do Brasil. Brasília: Senado Federal, 1988.

. Lei no 8.742, de 7 de dezembro de 1993 - Lei Orgânica da Assistência Social LOAS. Dispõe sobre a organização da Assistência Social e dá outras providências. Disponível em: <http://www.planalto.gov.br/ccivil_03/Leis/L8742.htm>. Acesso em: 18 abr. 2016.

. Lei no 12.435, de 6 de julho de 2011. Altera a Lei no 8.742, de 7 de dezembro de 1993, que dispõe sobre a organização da Assistência Social. Disponível em: <https://www.planalto.gov.br/ccivil_03/_ato2011-2014/2011/lei/l12435.htm>. Acesso em: 18 abr. 2016.

Resolução CNAS no 109, de 11 de novembro de 2009. Tipificação Nacional de Serviços Socioassistenciais. Brasília, 2009.

. Resolução CNAS no 13, de 13 de maio de 2014. Tipificação Nacional de Serviços Socioassistenciais - Reimpressão 2014. Brasília, 2014.

Ministério do Desenvolvimento Social e Combate à Fome. Relatório de Programas e Ações do MDSA - Rio Grande do Norte. Disponível em: <http://aplicacoes.MDSA.gov.br/sagi/RIv3/geral/relatorio.php\#>. Acesso em: 25 out. 2015. 
. Ministério do Desenvolvimento Social e Combate à Fome. Orientações Técnicas: Centro de Referência de Assistência Social - CRAS. Brasília, 2009.

. Orientações Técnicas: Centro de Referência Especializado de Assistência Social CREAS. Brasília: Gráfica e Editora Brasil, 2011a.

Resolução CNAS no 145, de 15 de outubro de 2004. Política Nacional de Assistência Social. Brasília, 2004.

BRISOLA, E. M.A.; SILVA, A. L. da. O trabalho do Assistente Social no SUAS: novos desafios e velhos dilemas. In: . (Org.). O trabalho do Assistente Social no SUAS: entre velhos dilemas e novos desafios. Taubaté-SP: Cabral Editora e Livraria Universitária, 2014.

CONSELHO FEDERAL DE SERVIÇO SOCIAL. Trabalhar na Assistência Social em defesa dos direitos da Seguridade Social. Brasília, 2011.

IAMAMOTO, M. V. Renovação e Conservadorismo no Serviço Social: Ensaios críticos. 2. ed. São Paulo: Cortez, 1994.

. O Serviço Social na Contemporaneidade: trabalho e formação profissional. 15. ed. São Paulo: Cortez, 2008.

IBGE.Estados@ Rio Grande do Norte-IBGE. Disponível em:

<http://www.ibge.gov.br/estadosat/perfil.php?sigla=rn> . Acesso em: 25 ago. 2015.

RIO GRANDE DO NORTE. Fundação Estadual da Criança e do Adolescente. Programas. Disponível em: <http://www.fundac.rn.gov.br> . Acesso em: 25 ago. 2015a.

RIO GRANDE DO NORTE. Ministério Público do Estado do Rio Grandedo Norte. Relatório Final Projeto Conviver SUAS - estrutura física, recursos humanos e serviços socioassitenciais . Natal. 2015b.

RIO GRANDE DO NORTE. Secretaria de Estado do Trabalho, da Habitação e da Assistência Social. Missão e Programas. Disponível em: <http://www.sethas.rn.gov.br> Acesso em: 25 out. 2015 c.

SARAIVA, J. B. C. Adolescente em Conflito com a Lei: da indiferença à proteção integral uma abordagem sobre a responsabilidade penal juvenil. 2. ed. Porto Alegre: Livraria do advogado, 2005.

SOUZA. M. C. S. Ministério Público e o Princípio da Obrigatoriedade - ação civil pública ação penal pública. São Paulo: Método, 2007.

SPOSATI, A.O. et al. Assistência na trajetória das Políticas Sociais Brasileiras: uma questão em análise. 6. ed. São Pulo: Cortez, 1995.

Recebido em: 02/11/2015

Aprovado em: 28/10/2016 